\title{
Militarização das escolas públicas no Distrito Federal: projetos de gestão em disputa
}

\author{
Edileuza Fernandes Silva ${ }^{1}$ \\ http://orcid.org/0000-0002-9837-2958 \\ Maria Abádia da Silva ${ }^{2}$ \\ http://orcid.org/0000-0001-6048-077X
}

\begin{abstract}
Resumo
Discute-se a militarização de escolas públicas com ênfase no modelo de gestão compartilhada instituído no Distrito Federal em 2019 em um contexto de acirramento de ideário político conservador, que atenta contra os princípios da gestão democrática previstos na Constituição Federal de 1988, na Lei de Diretrizes e Bases de Educação Nacional no 9.394/96 e na Lei Distrital no 4.751 de 2012. Questiona-se em que medida esse modelo de gestão interfere na atuação do diretor para organizar e sistematizar o projeto político-pedagógico da escola. Em termos teórico-metodológicos, fundamenta-se em documentos legais, bibliografia sobre a temática e dados de entrevistas realizadas com gestores eleitos. As reflexões enfatizam que a militarização compõe projeto de imposição da ordem e correção de condutas juvenis pela combinação de dispositivos disciplinares, hierárquicos, correcionais e morais confrontando o projeto democrático de educação e enfraquecendo a atuação do diretor, democraticamente eleito, para fazer a gestão do projeto políticopedagógico da escola.
\end{abstract}

Palavras-chave: Educação. Gestão Democrática. Militarização das escolas públicas. Distrito Federal.

\begin{abstract}
The militarization of public schools is discussed with emphasis on the shared management model instituted in the Federal District in 2019 in a context of intensifying conservative political ideas, which undermines the principles of democratic management provided for in the Federal Constitution of 1988, in the Guidelines Law and Bases of National Education n 9.394/96 and District Law n. 4.751 of 2012. It is questioned to what extent this management model interferes with the principal's action to organize and systematize the school's political-pedagogical project. In theoretical and methodological terms, it is based on legal documents, bibliography on the subject and data from interviews with elected managers. The reflections emphasize that militarization is a project of imposing order and correcting juvenile conduct by combining disciplinary, hierarchical, correctional and moral provisions confronting the democratic project of education and weakening the role of the democratically elected director to manage the project political-pedagogical school.
\end{abstract}

Keywords: Education. Democratic management. Militarization of public schools. Federal District.

\footnotetext{
${ }_{1}$ Doutora em Educação. Professora Adjunta da Faculdade de Educação da Universidade de Brasília na área de Didática e do Programa de PósGraduação na Linha de Pesquisa Profissão Docente, Currículo e Avaliação. E-mail: edileuzafeunb@gmail.com

2 Doutora em Educação. Atua no Programa Pós-Graduação em Educação da Faculdade de Educação - UnB e desenvolve estudos e pesquisas na área da Educação com prioridade para a História da Educação do Distrito Federal e Organismos Internacionais, políticas e gestão da Educação Básica. E-mail: “mailto:abadiaunb@gmail.com”abadiaunb@gmail.com
} 


\section{Introdução}

No Brasil, tem crescido a adesão de governos estaduais à política militarização das escolas públicas da educação básica, sob a gestão da Polícia Militar e/ou do Corpo de Bombeiros, baseado no argumento de que esse modelo resolverá problemas disciplinares e de violência, com vistas a alcançar melhores resultados na educação. Segundo Santos e Pereira (2018), o estado de Goiás tornou-se referência no processo de militarização, seguido pelos estados do Amazonas, Mato Grosso, Minas Gerais e Roraima. Acompanhando esse movimento, o Distrito Federal (DF), em 2019, compartilhou a gestão de nove escolas públicas com instituições militares que passaram a se responsabilizar pela gestão administrativa e "disciplinar-cidadã".

Esse movimento tende a avançar com o Decreto $\mathrm{n}^{\circ} 10.004$ de 5 de setembro de 2019 , assinado pelo presidente Jair Bolsonaro, que regulamenta a adesão de Estados e do Distrito Federal ao Programa Nacional das Escolas Cívico-Militares (PECIM), que visa promover gestão de excelência "nas áreas educacional, didático-pedagógica e administrativa, baseada nos padrões de ensino adotados pelos colégios militares do Comando do Exército, das polícias militares e dos corpos de bombeiros militares” (BRASIL, 2019). Desde então, dezesseis unidades da federação, incluindo o DF e cerca de 650 municípios, manifestaram interesse em aderir ao Programa, que tem como meta implementar 216 escolas cívico-militares até 2023. Para isso, serão disponibilizados recursos financeiros de $\mathrm{R} \$ 1$ milhão por escola, totalizando um investimento de R\$54 milhões, para pagamento de pessoal, melhoria de infraestrutura, compra de material escolar, uniformes, entre outros. ${ }^{3}$

Com essa política, delega-se aos militares, cujas atribuições constitucionais incluem "a polícia ostensiva e a preservação da ordem pública" (BRASIL, 1988), a gestão das escolas, desconsiderando-se que a organização do trabalho escolar pressupõe articulação entre as dimensões intencionais e intransferíveis - pedagógica, administrativa, financeira e político-participativa, a serem desenvolvidas por profissionais da educação com formação pedagógica. O controle da "gestão de excelência", por meio de avaliações externas, reforça a lógica de responsabilização de gestores, professores e estudantes, com implicações sobre a gestão pedagógica, dimensão central do trabalho escolar por ser responsável pelo cumprimento das finalidades das instituições.

Nesse contexto, o objeto deste artigo desenvolve-se em torno de algumas indagações: militarização, que fenômeno é este? Quais as implicações das legislações federal e distrital que instituíram a militarização nas escolas públicas para a gestão democrática? Que finalidades da educação básica estão encobertas? Em que medida a separação da dimensão pedagógica e administrativa do trabalho do diretor interfere na gestão do projeto políticopedagógico, que organiza e sistematiza o trabalho da escola e que tem o gestor como articulador? Urge discutir essa política para se entender o lugar da gestão democrática preconizada pela Lei 4.751/2012 que dispõe sobre essa forma de gestão no sistema público de ensino do DF.

Com essas reflexões iniciais, parte-se, em termos teórico-metodológicos, da análise de documentos oficiais dos governos federal e distrital: i) que expressam um fragmento da realidade nas circunstâncias históricas temporais e espaciais analisadas; ii) cujas arenas de poder apresentam um intrincado jogo de forças entre grupos dominantes que conseguem impor seus pleitos; iii) que podem revelar aquilo que não está registrado, mas que integra o

\footnotetext{
Cerca de 650 municípios manifestaram interesse em implantar escolas cívico-militares Disponível em: http://portal.mec.gov.br/component/ content/article?id=81311. Acesso: 18 de out. 2019.
} 
movimento real concreto; e vi) cujas orientações na legislação ou em documentos podem distanciar-se do real, pois é no real que as práticas sociais encontram barreiras ou são incorporadas na lei e ganham concretude e corpo. Serão também utilizadas informações levantadas de questionários aplicados a gestores de escolas da rede pública de ensino do DF, em estudo sobre percepções acerca do seu trabalho na gestão democrática.

A abrangência da política nacional de militarização - incluindo seus fundamentos, princípios, intencionalidades e valores disseminados nos sistemas de ensino público - exige uma análise crítica que qualifique os debates e fundamente a resistência e a defesa da gestão democrática. Com esse intuito, o artigo está organizado em três partes: a primeira, analisa a proposta de formação de tropas e oficiais nos colégios militares no Brasil; a segunda discute os projetos em disputa na gestão das escolas públicas do DF; e a terceira versa sobre a gestão do projeto político-pedagógico face à política de militarização das escolas.

\section{A proposta de formação de tropas e oficiais dos colégios militares no Brasil}

De fato, discutir a gestão administrativa e pedagógica em escolas da educação básica do DF transformadas em cívico-militares requer uma breve busca da proposta de formação dos colégios militares no País, após a chegada da Coroa Portuguesa no Brasil, quando D. João VI criou, em 1808, a Real Academia Marinha e, em 1810, a Real Academia Militar com o objetivo:

[...] de formar oficiais de infantaria e de cavalaria, para as operações de guerra, e formar oficiais de artilharia e oficiais engenheiros, incluindo geógrafos e topógrafos, aptos para direção de construção de estradas, pontes, portos e aprimoramento do Corpo de Tropas e da formação de um Exército que fosse capaz de fazer frente às constantes ameaças de invasões na costa brasileira (NOGUEIRA, 2014, pp. 155-163).

A proposta do Exército era de um ensino voltado para as atividades eminentemente militares, em detrimento de uma formação humanística e crítica que levasse os soldados a se envolverem em questões políticas. A despeito disso, conforme informa o autor, nos anos de 1920, a Escola Militar do Realengo se diferenciava das demais pela "politização de parte de seus alunos" (NOGUEIRA, 2014, p. 157), especialmente dos que se distinguiam do grupo, cuja formação visava atividades profissionais, sinalizando que, mesmo em instituições educativas militares, há socialização por meio do processo formativo para que os sujeitos assumam diferentes papeis na sociedade: de comando e de comandado.

A primeira Lei de Ensino Militar, de 1928, tinha como objetivo formar tropas oficiais e quadros com aptidões para a carreira militar e dispunha sobre:

[...] o ensino militar ampliando a sistematização de cursos para um conjunto de 12 Escolas de Formação do Exército Brasileiro. Foi criada a Escola de Engenharia Militar, Instituto Militar de Engenharia (IME), órgão anexo ao Sistema Militar do Exército com especializações em várias modalidades de engenharia: engenheiro-artilheiro, engenheiro-eletrotécnico, engenheiro-químico e engenheiro de construção (LUCHETTI, 2006, p. 89).

No Distrito Federal, o Colégio Militar de Brasília (CMB) foi criado pelo então presidente da República, General Ernesto Geisel, por meio do Decreto $\mathrm{n}^{\circ}$ 81.248, de 23 de janeiro de 1978, cujas atividades foram iniciadas em 5 de março de 1979, para atender aos filhos de militares da três Forças Armadas e Forças Auxiliares. O 
Colégio atendia, ainda, estudantes civis aprovados em concurso público, realizado anualmente, e contemplava os ensinos fundamental e médio. Dentre os objetivos da proposta pedagógica do $\mathrm{CMB}^{4}$ destacam-se: a) permitir ao aluno desenvolver atitudes e incorporar valores familiares, sociais e patrióticos que lhes assegurem um futuro de cidadão patriota, cônscio de seus deveres, direitos e responsabilidades, qualquer que seja o campo profissional de sua preferência; b) desenvolver no aluno a visão crítica dos fenômenos políticos, econômicos, históricos, sociais e científico-tecnológicos, ensinando-o, a aprender para a vida. As finalidades da educação são: I. a formação integral de cidadãos autônomos, éticos, solidários e atuantes social e politicamente por intermédio do trabalho e do desenvolvimento dos campos afetivo, cognitivo e psicomotor; II. oferta de educação para os filhos daqueles que acreditam nos valores que orientam a tradição militar, a cultura, o modo de fazer e de agir do Exército Brasileiro num ambiente hierarquizado e disciplinado; III. atendimento dos dependentes de militares de carreira do Exército, e dos demais candidatos, por meio de processo seletivo.

Observe que a constituição da educação militar no país serve aos diferentes objetivos de defesa, hierarquia, disciplina e valores da corporação. Nas palavras de Nogueira:

[...] a simples agregação do termo militar à educação já desperta interesse. No dicionário encontramos as seguintes definições: mi.li.tar adj (lat militares). 1. Que diz respeito à guerra, à milícia, às tropas. 2. Que se baseia na força militar ou nos costumes militares. 3. Determinado pelas leis da guerra. 4. Pertencente ao exército (em contraposição a civil). 5. Próprio de quem segue a carreira das armas, tendo como função específica a defesa da Pátria. 6. Que ama a carreira das armas. SM. Aquele que faz parte do exército ou segue a carreira das armas; soldado (NOGUEIRA, 2014, p. 147).

O autor acrescenta que "o termo militar serve para indicar os profissionais ou membros das instituições que possuem a autorização para o "uso legítimo da força"” (p.147). Assim, sem desconsiderar a relevância dos objetivos da formação no Colégio Militar, expressos em sua proposta pedagógica, parte-se do pressuposto que essa perspectiva formativa demanda um modelo de gestão pedagógica e administrativa distante do que se entende por gestão democrática pautada em princípios de participação, autonomia, transparência, democratização das relações pedagógicas e de trabalho e respeito à diversidade, à pluralidade e ao caráter laico da educação. O "uso legítimo da força", indicado pelo termo militar, não coaduna com processos formativos dos sujeitos sociais e históricos que frequentam as escolas públicas de educação básica. Diante disso, importa compreender a gestão democrática como princípio constitucional, como possibilidade de cumprir as finalidades e objetivos da educação básica, no DF normatizada pela Lei no $4.751 / 2012$, de Gestão do Sistema Público de Ensino.

\section{A gestão das escolas públicas do Distrito Federal: projetos em disputa}

A gestão democrática foi inscrita na Constituição Federal de 1988, art. 206, com ênfase nos direitos sociais e humanos, tendo a Lei 9.394/96 preconizado os princípios que caracterizariam a gestão de escolas dos sistemas públicos de ensino como democrática. A instituição da gestão democrática como princípio em lei, resulta de ações e manifestações de entidades e associações científicas e das lutas dos movimentos sociais que puseram em marcha a defesa de um projeto de sociedade justo, plural e democrático. Ao mesmo tempo, entre 1988 e 1995 experts de instituições multilaterais e outros intelectuais que ocuparam cargos em órgãos executivos de diferentes governos

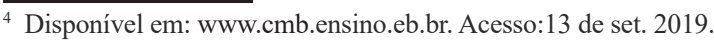


no País criaram o conceito gestão compartilhada, na esteira das políticas de descentralização dos serviços de saúde e educação, para se distinguir daqueles que defendiam a gestão democrática.

Ainda em 1995, governos neoliberais e neoconservadores trouxeram do Reino Unido e dos Estados Unidos o conceito da Nova Gestão Pública, caracterizada pela defesa da privatização, livre mercado, competitividade, parcerias público-privadas, descentralização, contratos de gestão, produtividade, terceirização, avaliação em larga escala e accountability para transportar e instalar práticas gerencialistas no sistema público de ensino. Esse movimento se intensificou com o Plano Diretor de Reforma do Aparelho do Estado (BRASIL, 1995), e com a Emenda Constitucional (EC) nº 19/98 (BRASIL, 1998), que explicita uma concepção de administração pautada pela eficiência, superação da gestão burocrática, redução e otimização de gastos e, consequentemente, redução do tamanho e das atribuições do Estado. Com isso, as parcerias entre Estado e entidades de direito privado sem fins lucrativos foram incentivadas, com repercussões para a educação pública. Nessas circunstâncias históricas de reprodução do capital, conglomerados transnacionais, empresários, filantropos e governos neoconservadores elevaram a educação a um negócio (SILVA; PEREIRA, 2018) a ser tratado por economistas, empresários, grupos internacionais e juristas (FRIGOTTO, 1999).

Atualmente, no âmbito federal, inúmeras ações têm sido tomadas nesse sentido: a aprovação da Emenda Constitucional 95/2016, da reforma trabalhista e da previdência; a Lei ${ }^{\circ} 13.429 / 2017$, que dispõe sobre a terceirização, inclusive das atividades meio e fins no setor público e privado; a Lei da liberdade econômica; o Projeto Future-se (2019), que visa à aproximação das universidades com o setor empresarial e o fortalecimento da autonomia administrativa e financeira das Instituições Federais de Ensino Superior (IFES), por meio da parceria com Organizações Sociais (OS). O fomento à captação de recursos próprios e a reforma tributária são exemplos de recomposição de terreno para salvar, proteger e expandir os nichos de reprodução do capital. É nesse contexto político e jurídico que situam-se os atos administrativos que recorrem a dispositivos coercitivos e de persuasão para mitigar e encobrir velhas questões estruturais e de desalento dos estudantes em relação às expectativas de melhoria de sua condição social e familiar. Tais atos expressam o posicionamento político e ideológico do grupo que assumiu o governo federal a partir de 2019.

Nesse cenário, a gestão das escolas públicas do Distrito Federal evidencia uma constante disputa política e ideológica, tornando a gestão democrática um projeto difícil de se concretizar, mesmo diante das experiências vivenciadas em períodos e governos anteriores. Os embates revelam projetos antagônicos do ponto de vista conceitual e das práticas. De um lado, está o projeto que representa setores comprometidos com a escola pública e democrática e lutam para firmar a gestão democrática como política de Estado; de outro, um projeto que representa os interesses de grupos empresariais que veem a gestão da educação como possibilidade para atender às demandas do setor produtivo, entendendo a educação como mercadoria.

As escolas públicas do Distrito Federal convivem, paradoxalmente, com os limites e as barreiras burocráticas e com lentidão administrativa no atendimento às demandas pedagógicas e financeiras devido aos constantes atrasos e incertezas nos repasses de verbas do Programa de Descentralização Administrativa e Financeira (PDAF) $)^{5}$ e com práticas e processos de gestão democrática; mas estão sujeitas à adoção de modelos flexíveis, contratos de gestão, parcerias público-privadas, presença de Organizações não Governamentais (ONG), parcerias com Organizações

Escolas públicas do DF arrecadam dinheiro com pais e alunos para manutenção e merenda. Disponível em: https://g1.globo.com/df/distritofederal/noticia/2019/10/17/escolas-publicas-do-df-arrecadam-dinheiro-com-pais-e-alunos-para-manutencao-e-merenda.ghtml. Acesso: 25 de out. 2019. 
Sociais (OS) para a oferta da educação infantil. Estudos de Flores e Peroni (2018) destacam que as manifestações, lutas e disputas de propostas ocorrem junto aos poderes Executivo e Legislativo, explicitando discordâncias e dissensos entre as forças políticas, as intenções dos empresários do ensino e os interesses dos segmentos sociais.

Desse modo, entende-se que, no movimento político e social atual, a legislação educacional expressa os embates entre forças em disputa, resultantes das práticas sociais que almejam imprimir diferentes modelos de gestão escolar. Em outras palavras, a legislação educacional carrega e transporta os "dissensos na sua dinamicidade de elaboração e de realização, portanto, ordena as relações socioeducacionais" (FARIA FILHO, 1998, p. 98) e expressa disputas de projetos entre forças políticas e segmentos sociais antagônicos que procuram fazer valer suas propostas e convicções.

No DF, esse processo não foi diferente. Aqui forças políticas, entidades sindicais e movimentos sociais disputam seus projetos de gestão da escola. Entre 1995 e 1998, o governador Cristovam Buarque, sancionou a Lei no 957/1995 de Gestão Democrática que tinha como princípio a "escolha dos diretores da unidade de ensino, com participação direta da comunidade" (DISTRITO FEDERAL, 1995) e reforça o papel do conselho escolar; de 1999 a 2006, Joaquim Roriz altera a lei de gestão anterior e aprova a Lei no 247/1999 com supressão do item que previa autonomia da gestão nas escolas nos aspectos administrativo, pedagógico e financeiro e retira o poder de decisão da comunidade escolar na escolha de diretor e vice; em seguida, entre 2007 e 2010, José Roberto Arruda sancionou a Lei 4.036/2007 que institui a gestão compartilhada como forma de provimento ao cargo de diretor e vice por meio de avaliação de conhecimentos com prova objetiva e eliminatória, apresentação de plano de trabalho e eleição direta (SANTOS; JESUS, 2018); entre 2011 e 2014, Agnelo Queiroz sancionou a Lei 4.751/2012, elaborada em amplo debate envolvendo diferentes segmentos da educação.

Em 2019, o governador Ibaneis Rocha, mantém a Lei de 2012 e instituiu a Portaria Conjunta n ${ }^{\circ} 1 / 2019$, que estabelece e reparte a gestão das escolas públicas em administrativa, disciplinar-cidadã e pedagógica. Em sintonia com o ideário conservador do Governo Federal, esse projeto político de Gestão Compartilhada - disciplinador de corpos e mentes juvenis da escola básica pública - impulsiona a lógica da ocupação do setor público pelo privado, com a presunção de melhoria da qualidade, aferida pelas avaliações externas, a despeito do desempenho evidenciado pelos alunos das escolas militarizadas no Exame Nacional do Ensino Médio (Enem), considerados semelhantes ao de estudantes dos institutos federais, conforme reportagem da Folha de São Paulo de 18 de fevereiro de $2019^{6}$.

Em 2019, o sistema educacional público do DF, que tem atribuições de estado e de município, constituise de 683 escolas e 26.956 mil professores para atender cerca de 450 mil estudantes ${ }^{7}$. Os profissionais da rede pública obtiveram, por meio de lutas históricas e com ações sindicais organizadas, conquistas como: jornada de trabalho de 40 horas para docentes em uma única escola; carga horária de 15 horas semanais destinadas ao planejamento, formação continuada, estudos, discussões em espaços-tempos de coordenação pedagógica; piso salarial acima do teto definido por lei; carreira docente qualificada, 1809 mestres e 264 doutores; investimento na formação continuada dos profissionais com licença remunerada para estudos; concurso público. Destaca-se, ainda, o Currículo da Educação Básica, elaborado com o protagonismo de estudantes e profissionais da educação no período de 2011 a 2014.

\footnotetext{
${ }^{6}$ Escolas militares e colégios civis com mesmo perfil têm desempenho similar. Disponível em: https://www1.folha.uol.com.br/educacao/2019/02/ escolas-militares-e-colegios-civis-com-mesmo-perfil-tem-desempenho-similar.shtml. Acesso: 25 de out. 2019.

${ }^{7}$ Dados do Censo Escolar 2018. Disponível em: http://www.se.df.gov.br/censo-escolar/. Acesso: 18 de out. 2019.
} 
Nesse cenário, a gestão democrática expressa um projeto educacional que prima pelo trabalho coletivo com a participação da comunidade, com vistas à garantia do direito à educação. Em contrapartida, a implantação da Gestão Compartilhada divide as dimensões do trabalho do gestor escolar, ficando a dimensão administrativa e disciplinar para os militares e a dimensão pedagógica para um diretor, profissional da educação. Essa compartimentalização do trabalho do gestor favorece a perda do seu sentido político-pedagógico e redefine o cumprimento das finalidades da educação.

Estudos realizados por Araújo (2012), Sato (2019) e Moreira (2019) indicam que, sob circunstâncias históricas, sociais e políticas, a gestão democrática no DF vem sendo aniquilada e confrontada, na esteira de expansão de negócios neoliberais conduzidos por grupos econômicos transnacionais, filantropos e governos neoconservadores, e se intensificou a partir do governo José Roberto Arruda (2007-2010), que instituiu a Lei Distrital n 4.036/2007, que dispôs sobre Gestão Compartilhada, com mecanismos que travavam as práticas de decisões coletivas e participativas na gestão administrativa e pedagógica. Essa perspectiva foi recuperada com nova roupagem pelo governo Ibaneis Rocha, pela Portaria Conjunta nº 1 de 2019 da Secretaria de Educação e Secretaria de Segurança Pública do DF, que dispõe sobre a implementação de Projeto Piloto de Gestão Compartilhada para transformar as escolas públicas em Colégios da Polícia Militar, como estratégia para conter a indisciplina no ambiente escolar e melhorar o desempenho dos estudantes.

Diante desse quadro, indaga-se: quais serão as modificações na gestão administrativa e pedagógica das escolas públicas que aderirem ao modelo dos colégios militares? Que interesses estão encobertos nessa política? Por que, ao invés de implementar o Plano Nacional de Educação (2014-2024) - que na Meta 19 aponta como atribuição dos sistemas de ensino: "assegurar condições para a efetivação da gestão democrática da educação" - o governo atual busca mecanismos para enfraquecê-lo por meio de políticas que visam moldar mentes e corpos de estudantes e educadores? São questões que inquietam pesquisadores e para as quais buscam-se outras alternativas por meio de estudos e pesquisas.

A Portaria Conjunta $\mathrm{n}^{\circ} 1$ de 2019 , art. $3^{\circ}$, parágrafo $2^{\circ}$ indica que a gestão escolar será híbrida: I - Gestão Estratégica - $\mathrm{PMDF}^{8} / \mathrm{SEEDF}^{9}$; II - Gestão Disciplinar Cidadã - PMDF; e III - Gestão Pedagógica - SEEDF. Esta última ocorrerá sob responsabilidade dos diretores eleitos conforme Lei Distrital 4.751 de 7 de fevereiro de 2012, que dispõe sobre a gestão democrática do sistema público de ensino do DF e contempla: eleição de diretores, autonomia para a elaboração de projeto político-pedagógico, Fórum Distrital de Educação, Conferência Distrital de Educação, assembleia escolar, grêmios estudantis, conselhos escolares, formação de diretores eleitos e outros mecanismos que favorecem a gestão democrática e a consecução dos objetivos e intencionalidades dos projetos pedagógicos das escolas.

De modo que, ainda na vigência da Lei 4.751/2012, o governador sancionou a Portaria Conjunta nº 1 de 2019 e instituiu o Projeto Gestão Compartilhada Cívico-Militar, o que significa dizer que a gestão de algumas escolas públicas da rede de ensino do DF foi transferida para a Polícia Militar, desconsiderando-se que as finalidades da educação são diferentes nos colégios militares e na instituição escolar civil pública, regulamentada pela Constituição Federal de 1988 (CF) e pela Lei de Diretrizes e Bases da Educação Nacional (LDBEN) nº 9.394/96.

Diante disso, faz-se necessário recuperar a finalidade da educação pública, contemplada no Currículo da Educação Básica da rede pública do DF (DISTRITO FEDERAL, 2014), que assumiu a Pedagogia Histórico-

\footnotetext{
${ }^{8}$ Política Militar do Distrito Federal.

9 Secretaria de Estado de Educação do Distrito Federal
} 
Crítica como pressuposto teórico e o trabalho educativo como "o ato de produzir, direta e intencionalmente, em cada indivíduo singular, a humanidade que é produzida histórica e coletivamente pelo conjunto dos homens" (SAVIANI, 2008, p.13). Ao mesmo tempo, Freitas (2016, p. 207) assevera que "as teses da Pedagogia HistóricoCrítica são importantes, pois orientaram e orientam ainda muito da nossa compreensão da questão da organização do trabalho pedagógico".

Essa compreensão situa a escola como uma instituição marcada por contradições e conflitos entre o desenvolvimento das forças produtivas e as relações sociais de produção. A natureza contraditória da escola pode indicar a superação dessas contradições articuladas ao mundo do trabalho à medida que a escola assume a tarefa de garantir a apropriação dos conhecimentos historicamente constituídos pela humanidade, de forma a favorecer a emancipação humana. Entende-se que esse projeto requer uma gestão democrática, incompatível com o projeto de gestão compartilhada instituída no DF.

Num movimento complexo e heterogêneo, gestores, docentes, discentes e sindicatos disputaram e disputam com governos de distintos partidos políticos, projetos de gestão para fazer prevalecer a participação, o diálogo e a construção de projetos educacionais. Entretanto, o modelo de Gestão Compartilhada (2019) em discussão e implementação no DF tem seduzido as famílias dos estudantes e até mesmo professores, com o argumento forte da garantia da segurança no interior da escola, desconsiderando que a insegurança é uma questão estrutural da sociedade, decorrente das desigualdades sociais, concentração da renda, altos privilégios para poucos e empobrecimento da maioria da população que marcam o modelo de organização das relações produtivas na sociedade capitalista.

Se, com avanços, recuos e limites os princípios da gestão democrática - participação, transparência, autonomia da escola, pluralismo e respeito à diversidade - passaram a fazer parte das práticas administrativas e pedagógicas, novamente, as velhas práticas autoritárias de punição, emulação, rigorosa disciplina, meritocracia, competição, uniformização, vigilância hierárquica, identidade padronizada, sujeição, ordem e comportamento moral são instituídas para domesticar, endireitar corpos e mentes por meio da educação. Esse alinhamento do Governo do Distrito Federal (GDF) às políticas federais corrobora o desmonte de um projeto educacional democrático, afrontando a autonomia das escolas públicas e de seus projetos pedagógicos.

Com esse intuito, no Distrito Federal, durante as férias de janeiro de 2019, a Secretaria de Educação convocou a comunidade escolar - famílias, estudantes e profissionais da educação de quatro escolas públicas - para aprovar de maneira açodada, sem discussão, tendo em vista tratar-se de um período de férias escolares, o Projeto Piloto de Gestão Compartilhada cívico-militar. De acordo com o art. $1^{\circ}$ da Portaria Conjunta $n^{\circ} 01$, o projeto tem como finalidade "proporcionar uma educação de qualidade, bem como construir estratégias voltadas ao policiamento comunitário e ao enfrentamento da violência no ambiente escolar, para promoção de uma cultura de paz e o pleno exercício da cidadania" (DISTRITO FEDERAL, 2019).

Essa ação do governo repetiu-se no período de férias escolares do mês de julho de 2019, para estender o projeto a outro conjunto de escolas, sendo que duas deliberaram pela não adesão. Diante da recusa, o governador do DF, Ibaneis Rocha, desrespeitando as decisões das duas escolas, expressou publicamente ${ }^{10}$ que: "Democracia foi no dia que me elegeram governador com mais de um milhão de votos. Me escolheram para poder fazer a mudança, mudar para melhor. Quem governa sou eu, os que estiverem insatisfeitos com a gestão compartilhada

\footnotetext{
10 Disponível em: https://www.metropoles.com/colunas-blogs/grande-angular/ibaneis-implementara-gestao-compartilhada-com-a-pm-nas-escolas-que-rejeitaram-modelo. Acesso: 21 ago. 2019.
} 
busquem a justiça". Ao se manifestar sobre a recusa da escola, o governador afronta os princípios da gestão democrática e o art. 15 da LDBEN que garante às escolas dos sistemas públicos "progressivos graus de autonomia pedagógica e administrativa e de gestão financeira, observadas as normas gerais de direito financeiro e público" (BRASIL, 1996).

Observa-se que, nas escolas públicas do DF, estão em disputa dois modelos de gestão: a) compartilhada (2019) que não dispõe de diretrizes e orientações para subsidiar a gestão administrativa e pedagógica; e, b) democrática (Lei n 4.751/2012), pela qual o currículo da educação básica e diretrizes fundamentadas na Pedagogia HistóricoCrítica orientam o trabalho pedagógico. Portanto, sob resistência e imposição coexistem na gestão escolar (i) práticas de rigorosa disciplina, alunos enfileirados em posição de sentido, controle de corpos, farda, canto diário do Hino Nacional na entrada e na saída de turno; e (ii) práticas de manutenção da eleição de diretor escolar, de incentivo à construção do projeto pedagógico da escola e do trabalho.

O ato administrativo do governador Ibaneis Rocha (2019-2022) que parece extemporâneo, na verdade não o é. De fato, este projeto busca: i) revisitar atitudes, valores morais, cerceamento de condutas, visões e identidades, banimento de expressões culturais indesejáveis; ii) recompor os padrões civilizatórios da elite e restituir ordem e progresso; iii) reposicionar o lugar social das pessoas e fazê-las incorporar como devem se comportar; iv) transportar e carregar ideologias políticas, econômicas e morais; e, v) instituir formação escolar assentada na obediência, subordinação e submissão aos valores pregados pelo mercado. Reforça-se, assim, o papel da escola como meio de veiculação de valores, ideias, comportamentos, culturas e ideologias dos grupos sociais dominantes, que corroboram o amoldamento dos jovens estudantes às necessidades do mercado de trabalho ${ }^{11}$ e a exclusão dos que não se adequarem às normas e regras impostas pela gestão administrativa-disciplinar das escolas.

Assim, importa, pois, refletir em que medida a militarização interfere na atuação do diretor escolar a quem compete a gestão do projeto político-pedagógico da escola, central para a organização do trabalho escolar articulando as dimensões administrativa, pedagógica, financeira e participativa.

\section{A gestão dos projetos das escolas públicas militarizadas e o esvaziamento do trabalho do} diretor

As escolas públicas no Brasil são responsáveis pela matrícula de 39.460 .618 milhões de estudantes, do total de 48,5 milhões de matrículas na educação básica, conforme dados do Censo Escolar de 2018 do Ministério da Educação (MEC)/Instituto Nacional de Estudos e Pesquisas Educacionais Anísio Teixeira (INEP) ${ }^{12}$. No DF, de acordo com dados do Censo Escolar da SEEDF de 2019³, foram 456.109 matrículas nesse nível de ensino. Os dados do MEC também indicam que a qualidade da educação básica não melhorou e a estrutura física e tecnológica da maioria das escolas é precária. Uma em cada três escolas não tem acesso à internet e quase metade não tem biblioteca ou sala de leitura. No ensino médio, a situação é ainda mais grave, mais da metade não possui laboratório de ciências.

\footnotetext{
De acordo com Ciavatta (2019, p. 136) "[...] mercado de trabalho, onde ocorre a compra e venda da força de trabalho, o trabalho assalariado, o emprego e o desemprego, o trabalho precarizado, desregulamentado [...]".

12 Censo Escolar: notas estatísticas 2018. Inep: Ministério da Educação. Disponível em: http://download.inep.gov.br/educacao basica/censo escolar/notas_estatisticas/2018/notas_estatisticas_censo_escolar_2018.pdf. Acesso: 24 de out. 2019.

13 Censo Escolar 2019. Disponível em: http://www.se.df.gov.br/censo-escolar-2019/. Acesso:24 de out. 2019.
} 
Nesse contexto de poucos investimentos na educação pública, o governo do DF adota o discurso da diminuição da violência e melhoria da qualidade da educação para justificar a transferência da gestão administrativa e disciplinar de nove escolas $\left(\mathrm{CED}^{14} 3\right.$ de Sobradinho, CED Condomínio Estância II de Planaltina; CED 1 da Estrutural, CED 1 de Itapoã; CED 7 da Ceilândia; CED 308 do Recanto das Emas; CEF 1 do Núcleo Bandeirante; CEF 1519 de Taguatinga; e CEF 407 de Samambaia) localizadas em cidades em que a PMDF não tem conseguido garantir a segurança da população e o moradores convivem com índices de criminalidade comparados aos dos países mais violentos do mundo, como demonstra levantamento do Instituto de Pesquisa Econômica Aplicada (IPEA, 2019). ${ }^{16}$ Mesmo assim, deposita-se no policiamento o poder de resolver problemas de violência e indisciplina, como se eles fossem produzidos internamente sem conexões com o mundo exterior.

Essa escola pública, constitutiva e constituída da realidade brasileira, assume um papel mediador na formação de crianças e jovens, orientada por perspectiva conservadora ou transformadora definidora do tipo de projeto de formação que se pretende desenvolver. A defesa pela formação autônoma e emancipadora do ser humano para a consecução do que estabelece a Constituição Cidadã de 1988 passa, necessariamente, pela superação de práticas conservadoras neoliberais e antidemocráticas de ensinar, aprender, avaliar, viver e conviver que visam, como reflete Freitas (2018, p. 921), “aprisionar a escola para que ela não seja um polo de liberdade e incitação à transformação social". O pouco investimento em políticas públicas para a melhoria das condições de trabalho e de estudo nas escolas públicas parece estratégico para esse aprisionamento.

Nessa conjuntura de parcos investimentos, avança uma agenda conservadora que busca subordinar a escola pública a um projeto que visa o controle do trabalho de gestores e professores e de corpos e mentes dos estudantes. Esse controle recai sobre a organização do trabalho escolar como um todo, e da sala de aula especificamente, por meio do currículo escolar, dos métodos de ensino, da avaliação da aprendizagem dos estudantes, da relação professor-aluno. Um trabalho escolar sob as condições impostas pela militarização com suas regras, rituais, ideias e valores, tendo o diretor, eleito democraticamente, que conduzi-lo, é uma contradição no seio de um espaço cujo papel central é formar sujeitos capazes de compreender, interpretar e transformar o mundo.

A principal função do diretor da escola de educação básica é fazer a gestão do projeto político-pedagógico (PPP), documento que organiza e sistematiza o trabalho escolar, explicitando o compromisso social e político da escola com os reais interesses da sociedade. Esse compromisso se efetiva enquanto prática especificamente pedagógica para possibilitar o cumprimento da finalidade da escola (VEIGA, 1996). Para isso, as dimensões da gestão - pedagógica, administrativa, financeira e político-participativa - devem se articular para viabilizar o trabalho da escola "o qual envolve a elaboração do projeto político-pedagógico, a articulação e a dinamização do conselho de classe, a coordenação pedagógica coletiva, o desenvolvimento curricular" (FERNANDES SILVA, 2018, p. 85), o acompanhamento de questões disciplinares, a mediação de conflitos no interior da escola e a gestão de recursos públicos para viabilizar a implementação do PPP.

Ao compartilhar a gestão das escolas públicas, historicamente de competência de profissionais de carreira da Secretaria de Educação, o governo do DF expropria os gestores de funções de natureza administrativa, pois, conforme a Portaria Conjunta 1/2019, a Gestão Pedagógica é delegada aos diretores eleitos, enquanto a Gestão

\footnotetext{
${ }^{14}$ Centro Educacional, escola que atende estudantes dos anos finais do ensino fundamental e do ensino médio.

15 Centro de Ensino Fundamental, escola que atende estudantes dos anos finais do ensino fundamental.

${ }^{16}$ Atlas da Violência 2019. Disponível em: http://www.ipea.gov.br/atlasviolencia/. Acesso: 24 de out. 2019.
} 
Disciplinar e Administrativa é assumida pela Polícia Militar do Distrito Federal (PMDF). Essa separação comprova a fragmentação e a desqualificação da atuação gestora e reforça uma concepção de gestão distante da concepção de gestão democrática em vigor no sistema público de ensino do DF.

Paro (2015) alude sobre o caráter administrativo de toda prática pedagógica e as potencialidades pedagógicas de toda prática administrativa, mostrando que há uma relação indissociável entre ambas. Excertos de entrevistas realizadas com alguns diretores ${ }^{17}$ eleitos de escolas públicas do DF revelam que eles demonstram compreender a indissociabilidade entre as dimensões administrativa e pedagógica do seu trabalho:

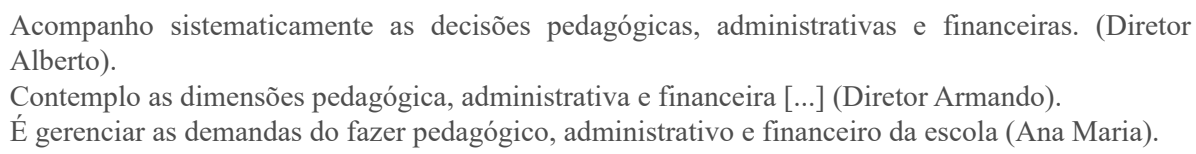

A gestão pedagógica complexa e abrangente constitui-se para atender à finalidade do trabalho escolar por meio de processos e práticas direcionadas à aprendizagem dos estudantes, melhoria dos resultados de desempenho da escola e elaboração, implementação, acompanhamento e avaliação do PPP. Nessa perspectiva, a atuação autônoma do diretor escolar reveste-se de sentido político-pedagógico, pois objetiva a democratização do acesso ao conhecimento historicamente acumulado pela humanidade, a formação e elevação das capacidades humanas e a busca de possibilidades transformadoras da realidade individual e social: "Gostaria de ter autonomia pedagógica, penso que as escolas poderiam desenvolver seus projetos sem que estejam atreladas a modelos institucionalizados pelo governo com objetivos meramente estatísticos", revela o diretor Cláudio, confirmando a análise de que a gestão compartilhada favorece a perda da visão de totalidade, o parcelamento do trabalho escolar e restringe a autonomia garantida pela Lei 4.751/2012 à escola para planejar, desenvolver e avaliar o seu PPP.

Chama a atenção, ainda, a ausência de diretrizes pedagógicas claras para as escolas que aderiram à militarização organizarem o trabalho pedagógico. Prevalecem o Currículo da Educação Básica e documentos fundamentados em uma perspectiva teórica crítica já enunciados, que não coadunam com a "padronização do sistema de ensino a partir de esquemas de planejamento previamente formulados, aos quais devem se ajustar as diferentes modalidades de disciplinas e práticas pedagógicas” (SAVIANI, 1994, p. 16).

Esse processo se agrava pelo fato de que os planejadores militares não possuem formação e competência técnica necessárias para atuar em processos de educação escolarizada. Como indica o art. $7^{\circ}$ da Portaria 1/2019, as escolas que aderirem ao projeto de Gestão Compartilhada, “deverão formular, aprovar e implementar um plano de gestão que garanta à Secretaria de Estado de Segurança Pública e à Polícia Militar do Distrito Federal autonomia para realizar a gestão administrativa-disciplinar [...]”. Questiona-se se essa autonomia da PMDF para elaborar um plano de gestão não sobrepõe ou subtrai a autonomia dos diretores escolares para desempenharem as funções legitimadas pela comunidade escolar em um processo democrático de escolha, conforme art. $2^{\circ}$ da Lei 4.751/2012.

De acordo com o art. $2^{\circ}$ da Portaria Conjunta n ${ }^{\circ} 1$ de 2019: "As funções de instrutor e monitor serão exercidas, preferencialmente, por policiais militares com restrição médica ao serviço operacional, policiais militares designados e policiais militares que estiverem em Prestação de Trabalho por Tempo Certo - PTTC". Ou seja, são profissionais com restrições para o exercício das atividades laborais inerentes à carreira militar, no entanto, para atuar em escola, não há restrições. Esse aspecto, além de revelar a pouca importância atribuída pelo Estado

\footnotetext{
Os nomes dos gestores são fictícios pelo fato de que as pesquisadoras assumiram o compromisso ético de garantia do anonimato dos sujeitos.
} 
ao trabalho escolar, caracteriza interferência no "campo científico" da educação e na "autoridade científica" dos educadores para atuar legitimamente em seu campo (BOURDIEU, 2003).

A ênfase em rituais dos quartéis merece reflexão: estudantes perfilados no pátio no início do turno escolar e a escuta do Hino Nacional diariamente, entre outros atos, subjugam os alunos e levam à perda de tempo que poderia ser destinado a pesquisas, leituras, trabalhos de grupo, auto-organização dos estudantes, debates, entre outras atividades pedagógicas (VILLAS BOAS, 2017).

A organização do trabalho da escola como um todo impacta o trabalho pedagógico de sala de aula, realizado por professores e estudantes. A Gestão Compartilhada que separa a gestão pedagógica da gestão administrativa da escola, o faz "porque esta última quase nunca é vista em sua essência, abstraída de seus condicionantes conjunturais que a tornam ou mera burocratização (meios que se tornam fins em si mesmos) ou mera gerência (controle do trabalho alheio)" (PARO, 2016, p. 43).

Assim, ao mesmo tempo em que defende-se a democracia como princípio e possibilidade de constituição de um projeto pedagógico e de gestão pautados pela tomada coletiva de decisões "cujo foco está no processo que leva à construção de trabalho colaborativo, constituindo-se espaço-tempo de possibilidades e de liderança pedagógica democrática" (FERNANDES SILVA; FERNANDES, 2017, p. 72) - que se concretiza por meio do protagonismo de professores, estudantes e gestores para tomarem nas mãos os rumos da escola, tarefa que não pode ser delegada a agentes externos sem formação pedagógica para tal empreitada - admite-se que a expansão das escolas militarizadas é uma realidade no DF, principalmente após publicação do Decreto no 10.004/2019 que institui o PECIM.

Nesse movimento, cabe identificar as formas de aniquilamento da gestão democrática, entre elas: a convivência em uma mesma rede de ensino de escolas com modelos de gestão díspares; a fragmentação da gestão enfraquecendo a atuação dos diretores, podendo fortalecer a divisão do trabalho no interior da escola; o trabalho administrativo desarticulado do trabalho pedagógico, tentativa de separar dimensões indissociáveis da gestão; a responsabilização de gestores, professores e estudantes pelos resultados aferidos pelas avaliações externas, conduzindo à regulação e ao controle sobre o trabalho pedagógico. Adicionam-se a isso, a desconsideração das vozes, reivindicações e propostas originárias da escola pública, tapeação e trapaça à participação, princípio basilar da gestão democrática.

Nesse contexto, urge organizar a resistência política e pedagógica com ações de fortalecimento da educação básica pública e da gestão democrática que incluem: valorização das experiências e processos de escolha de gestores por meio de eleição direta com a participação da comunidade escolar; tomada de decisões com os professores e diretor e não para eles executarem; reconhecimento e valorização dos trabalhadores da educação nas atividades de criação e elaboração de projetos com professores e estudantes; defesa da escola como espaço público que possibilita outros direitos sociais; esclarecimento da comunidade escolar para que compreenda os distintos projetos políticos e sociais que são postos na sociedade capitalista neoliberal. A resistência a esse modelo de gestão se faz pela organização pedagógica e política tendo o diretor escolar como articulador.

Portanto, militarização das escolas públicas caracteriza um fenômeno histórico, condutor de ideologias de "pureza"18 integrando elementos morais: constrangimento, controle simbólico, vigilância, obediência, sujeição

\footnotetext{
18 Remete a políticas e práticas conservadoras de eugenia social predominantes nos anos 1920 a 1930 e que objetivavam instaurar a ordem, o progresso e estabelecer o lugar das pessoas no território e difundir comportamentos e condutas adequadas para o padrão civilizatório europeu.
} 
e hierarquia social; elementos políticos: ordem e desempenho atrelados a indicadores de qualidade definidos externamente e atos autoritários; e elementos coercitivos: dispositivos disciplinares, por meio de castigo, privação, punição, premiação, sanção e emulação com a finalidade de restaurar um tipo de ordem e conduta para jovens pobres das escolas públicas.

Diante disso, a militarização reforça as distinções sociais ao associar a condição socioeconômica dos estudantes a atitudes consideradas desviantes do padrão dominante de comportamento desejável (FOUCAULT, 1996). Trata-se de decisão política que abstrai dos colégios militares, destinados à formação de tropas e oficiais, alguns princípios e os transporta para a formação civil-cidadã com a suposta intenção de disciplinar corpos e mentes de acordo com padrões civilizatórios e necessidades atuais de reprodução das relações sociais de produção.

\section{Para continuar as lutas e reflexões}

A gestão compartilhada em implementação no Distrito Federal (2019) retoma elementos e princípios dos colégios militares destinados a formar tropas, cadetes, praças e oficiais para o serviço militar do País e introduz práticas de premiação e punição, vigilância e controle, ordem e hierarquização em algumas escolas públicas, pondo em risco a gestão democrática e o alcance das finalidades da educação prescritas na Constituição Federal de 1988 e na Lei n ${ }^{\circ}$ 9.394/96, conquistas históricas e de lutas dos profissionais da educação. Adiciona-se, ainda, que o decreto do governo federal e a Portaria 1/2019 do governo distrital enfraquecem a Lei 4.751/2015 de gestão democrática do sistema público de ensino do DF.

Em um contexto político e educacional conservador, as finalidades da escola passam a ser socializar os sujeitos para atender às demandas dos processos produtivos e às exigências da ordem social, cumprimento de deveres, pontualidade, submissão, disciplina e contenção física necessários para o desenvolvimento dos processos de trabalho, e relegam o direito à educação de qualidade socialmente referenciada.

Ainda nesse contexto, as práticas gerencialistas neoliberais que insistem no diretor como coach escolar, favorecem o individualismo e, ao mesmo tempo, desarticulam o trabalho pedagógico ao dividir as dimensões da gestão, comprometendo a construção de um projeto de escola coletivo, plural, integrado, formativo e democrático. Desse modo, as finalidades da educação não estão encobertas. Estão explícitas na legislação e nas práticas que supõem formar corpos e mentes de trabalhadores e consumidores úteis para a reprodução e acumulação do capital.

Conclui-se, portanto, que enquanto os colégios militares, pela sua natureza, formam tropas, cadetes, praças e oficiais para execução de função de defesa, segurança e guarda das fronteiras territoriais do País, a escola pública, instituição social, tem compromisso coletivo, responsável pelo cumprimento do direito constitucional à educação, e destina-se à formação humana, intencional e integral para toda a vida. Preservá-la passa necessariamente pela defesa inconteste da gestão democrática.

\section{Referências}

ARAÚJO, A.C.de. Gestão, avaliação e qualidade da educação: políticas públicas reveladas na prática escolar. Brasília: Líber Livro; Faculdade de Educação/Universidade de Brasília, 2012. 
BOURDIEU, P. O campo científico. In: ORTIZ, R. (org.) A sociologia de Pierre Bourdieu. São Paulo: Olho d'Água, 2003.

BRASIL. Decreto n ${ }^{\mathbf{8 1}} \mathbf{2 4 8}$, de 23 de janeiro de 1978. Cria Organização Militar no Exército e dá outras providências. Câmara dos Deputados, Brasília, DF: 1978. Disponível em: https://www2. camara.leg.br/legin/fed/decret/1970-1979/decreto-81248-23-janeiro-1978-430212-publicacaooriginal1-pe.html. Acesso: 25 de out. 2019.

BRASIL. Constituição da República Federativa do Brasil de 1988. Brasileira, DF: Senado Federal. 2013.

BRASIL. Plano Diretor da Reforma do Aparelho do Estado. Brasília: Presidência da República, Câmara da Reforma do Estado, Ministério da Administração Federal e Reforma do Estado. 1995.

BRASIL. Lei $\mathbf{n}^{\mathbf{0}}$ 9.394, de 20 de dezembro de 1996. Estabelece as diretrizes e bases da educação nacional. Diário Oficial da União, Brasília, DF: 21 jul. 2014.

BRASIL. Emenda Constitucional n. 19/98, de 04 de junho de 1998. Modifica o regime e dispõe sobre princípios e normas da Administração Pública, servidores e agentes políticos, controle de despesas e finanças públicas e custeio de atividades a cargo do Distrito Federal, e dá outras providências. DOU. Brasília, 04 de jun. 1998.

BRASIL. Lei no 13.005, de 25 de junho de 2014. Aprova o plano Nacional de Educação. - PNE e dá outras providências. Diário Oficial da União, Brasília, DF: 21 jul. 2014.

BRASIL. Emenda Constitucional $\mathbf{n}^{\mathbf{0}}$ 95, de 2016. Altera o Ato das Disposições Constitucionais Transitórias, para instituir o Novo Regime Fiscal, e dá outras providências. Brasília, DF, 2016. Disponível em: https://www2.camara.leg.br/legin/fed/emecon/2016/emendaconstitucional-95-15dezembro-2016-784029-publicacaooriginal-151558-pl.html. Acesso: 25 de out. 2019.

BRASIL. Lei ${ }^{0}$ 13.429, de 31 de março de 2017. Altera dispositivos da Lei $\mathbf{n}^{0} \mathbf{6 . 0 1 9}$, de 3 de janeiro de 1974, que dispõe sobre o trabalho temporário nas empresas urbanas e dá outras providências; e dispõe sobre as relações de trabalho na empresa de prestação de serviços a terceiros. Brasília, DF: 2017. Presidência da República. Disponível em: http://www.planalto.gov. br/ccivil_03/_Ato2015-2018/2017/Lei/L13429.htm. Acesso: 25 de out. 2019.

BRASIL. Decreto $\mathbf{n}^{0} \mathbf{1 0 . 0 0 4}$, de 5 de setembro de 2019. Institui o Programa Nacional das Escolas Cívico-Militares. Brasília, DF. Disponível em: http://www.planalto.gov.br/ccivil_03/_ato20192022/2019/decreto/D10004.htm. Acesso em: 19 set. 2019. Acesso: 25 de out. 2019.

CIAVATTA, M. Trabalho-Educação: uma unidade epistemológica, histórica e educacional. Trabalho necessário, v. 17, n. 32, jan./abr. 2019.

DISTRITO FEDERAL. Lei n. 957, de 24 de novembro de 1995. Dispõe sobre a Gestão Democrática da Escola Pública e dá outras providências. Disponível em: http://www.tc.df.gov.br/. Acesso em: 15 nov. 2019. 
DISTRITO FEDERAL. Lei $\mathbf{n}^{\mathbf{0}}$ 4.751, de 7 de fevereiro de 2012. Dispõe sobre o Sistema de Ensino e a Gestão Democrática do Sistema de Ensino Público do Distrito Federal. Brasília, DF. Disponível em https://www.sinprodf.org.br/servicos/legislacao/. Acesso: 25 de out. 2019.

DISTRITO FEDERAL. Currículo em Movimento da Secretaria da Educação básica: Ensino Fundamental - Anos Iniciais. Brasília, 2014.

DISTRITO FEDERAL. Portaria Conjunta $\mathbf{n}^{\mathbf{0}} \mathbf{1}$, de 31 de janeiro de 2019. Dispõe sobre a implementação de Projeto Piloto de Gestão Compartilhada que prevê a transformação de quatro unidades específicas de ensino da rede pública do Distrito Federal em Colégios da Polícia Militar do Distrito Federal. Diário Oficinal do Distrito Federal, Brasília, DF: 1 de fevereiro de 2019.

FARIA FILHO, L. M. A legislação escolar como fonte para a história da educação: uma tentativa de interpretação. In: FARIA FILHO, L. M.; DUARTE, R. H. (et. alli). Educação, modernidade e civilização. Belo Horizonte: Editora Autêntica, 1998.

FERNANDES SILVA, E; FERNANDES, R.C.A. Coordenação pedagógica: espaço e tempo de organização do trabalho pedagógico coletivo. In: VILLAS BOAS, B.F. (org.). Avaliação: interações com o trabalho pedagógico. Campinas, SP: Papirus, 2017.

FERNANDES SILVA, E. Diretor da escola básica: “O vento que sopra o carvão". In: SILVA, M.A. da; PEREIRA, R. da (org.). Gestão escolar e o trabalho do diretor. Curitiba: Appris, 2018.

FLORES, M.L.; PERONI, V.M.V. Políticas públicas para a educação infantil no Brasil: desafios à consolidação do direito no contexto emergente da nova filantropia. Roteiro, Joaçaba, v. 43, n. 1, p. 133-154, jan./abr. 2018.

FRIGOTTO, G. Globalização e crise do emprego. Boletim Técnico do SENAC - DN, 25, nº 2, Rio de Janeiro, 1999.

FREITAS, L.C. Entrevista Luiz Carlos de Freitas: A organização do trabalho pedagógico no contexto atual do ensino público brasileiro. Crítica Educativa. Sorocaba, SP, v. 2, n.1, p. 202-226, jan.jun. 2016.

FREITAS, L.C. Escolas aprisionadas em uma democracia aprisionada: anotações para uma resistência propositiva. Revista HISTEDBR on-line. Campinas, SP, v. 18, n.4 [78], p. 906-926, out./dez./ 2018.

FOUCAULT, M. Vigiar e Punir: nascimento da prisão. Tradução Raquel Ramalhete, $13^{a}$ edição. Petrópolis: Vozes, 1996.

LUCHETTI, M.S.R. O ensino no exército brasileiro: histórico, quadro atual e reforma. 2006. Dissertação (Mestrado em Educação) - Faculdade de Ciências Humanas, Universidade Metodista de Piracicaba, Piracicaba, 2006.

MOREIRA, H.A.L. Política de formação do diretor escolar: trabalho pedagógico? Dissertação (Mestrado em Educação) - Faculdade de Educação-UnB, 2019.

NOGUEIRA J.G. Educação militar no Brasil: um breve histórico. In: Revista CAMINE: Caminhos da Educação, Franca, SP, v. 6, n. 1, 2014, p.146-172. 
PARO, V.H. Crítica da estrutura da escola. São Paulo: Cortez, 2016.

SANTOS, R.J.R; JESUS, W.F.de. A gestão escolar em Brasília: síntese histórica das concepções em disputa. Revista Com Censo. Brasília-DF, v. 5, n. 1, 2018, p. 36-43.

SATO, C. A. Gestão Escolar em duas escolas de ensino médio: o Programa de Ensino médio de tempo Integral- DF. Dissertação (Mestrado em Educação) - Faculdade de Educação - UnB, 2019.

SAVIANI, D. Escola e Democracia: teorias da educação, curvatura da vara, onze teses sobre educação e política. Campinas, SP: Mercado das Letras, 1994.

SAVIANI, D. Pedagogia Histórico-Crítica. Campinas: Editora Autores Associados, 2008.

SANTOS, C.; PEREIRA, R.S. Militarização e Escola Sem Partido: duas faces de um mesmo projeto.

Revista Retratos da Escola, Brasília, v. 12, n. 23, p. 255-270, jul./out. 2018.

SILVA, M. A; PEREIRA, R.S. Estado Capitalista brasileiro e organismos internacionais: continuidades das reformas educacionais. Revista HISTEDBR, on-line, v.18, série 1. p.523-544, 2018.

VILLAS BOAS, B. O dia a dia do trabalho pedagógico: contribuições para a formação do professor e dos estudantes. In: VILLAS BOAS, B. (org.) Avaliação: interações com o trabalho pedagógico. Campinas, SP: Papirus, 2017.

VEIGA, I.P.A. Projeto político-pedagógico da escola: uma construção coletiva. In: VEIGA, I.P.A. (org.). Projeto político-pedagógico: uma construção possível. Campinas, SP: Papirus, 1996. 